\title{
EL MINISTERIO JOVEN ADVENTISTA
}

Raúl Yaranga Pomasoncco Misión Nor Oriental rauly_isaias20@hotmail.com

Carlos Requejo Paico Asociación Nor Pacífico del Perú crequejop@hotmail.com

Walter Lapa Manrique Misión Centro Oeste del Perú walterglapa2@gmail.com

Fecha de recepción: Abril 2013 Fecha de aceptación y versión final: Junio 2013

\section{Resumen}

Arceño Infante Mendoza Misión Peruana del Norte prinfante@adventistasmpn.pe

Wilmer De la Cruz Ramos Asociación Peruana Central Este wiljaaziel@hotmail.com

Yessica Puerta Asto Unión Peruana del Norte yessica.puerta@adventistas.org.pe

Jaime Pérez Párraga Unión Peruana del Norte jaime.perez@adventistas.org.pe 
Summary: $\quad$ This article is a reaction to the eight modules of the youth ministries. The authors extend and develop the topic on how to apply the main principles governing the organization, leadership, worship, discipleship, fellowship, testimonies, dedication, training and the participation, on the work of Christian youth belonging to the Seventh-day Adventist Church.

Keywords: Mission, youth ministry, worship, discipleship, Christian leadership 


\section{Organización (módulo I)}

La primera organización juvenil en una Iglesia adventista surgió en 1879, cuando dos jóvenes, Harry Fenner de 16 años y Lutero Warren de 14 años, sintieron profunda preocupación por la indiferencia de algunos de sus amigos. Anhelosos de conducirlos a gozar de una experiencia cristiana más profunda, organizaron una sociedad de jóvenes, en un pequeño cuarto de la casa de los padres de Lutero, en Hazelton, Michigan.

En un inicio, estas reuniones fueron solo para varones, en la primera de ellas asistieron nueve jóvenes, pero tres meses después las reuniones ya eran mixtas. $\mathrm{El}$ propósito de aquel primer y pequeño grupo de jóvenes era promover la obra misionera, reunir dinero para comprar publicaciones misioneras, trabajar en favor de la causa de la temperancia y con ello apresurar la venida de Cristo. Planificado por Dios, esta sociedad, estaba destinada a crecer y a difundirse por todo el mundo.

\section{Cómo se desarrolló}

John Hancock organizó el primer club de Conquistadores en la Asociación del Sudeste de California, en 1946. De 1947 a 1950 el programa de los Conquistadores continuó desarrollándose en la Unión del Pacífico, bajo la dirección de J. R. Nelson, hasta que finalmente, en 1950, la Asociación General lo adoptó como un plan mundial.

En 1972 se le dio a esta fase de la obra el nombre de Departamento de Jóvenes Misioneros Voluntarios (MV), y los secretarios MV de las asociaciones recibieron el título de directores. En 1978 , en un nuevo cambio, se lo llamó Departamento de Jóvenes Adventistas, nombre que permanece hasta hoy.

El concilio otoñal de la Asociación General de 1927, realizado en Chattanooga, Tennessee, amplió el alcance de las Clases Progresivas al instituir tres clases para los menores (Amigo, Compañero y Guía), y una clase para 
los jóvenes. C. Lester Bond pasó a formar parte del departamento MV de la Asociación General en 1928, año en el que se añadieron dos importantes programas desarrollados para los jóvenes y adultos que "desearan prepararse para el liderazgo juvenil”: el programa de especialidades MV y la clase de Guías mayores. Los primeros Guías mayores fueron investidos en 1931.

Algunos años más tarde se comprendió el llamado que Dios hizo mediante los escritos de Elena G. de White, para que la Iglesia hiciera algo por los jóvenes. Escrito desde Melbourne, Australia, el 19 de diciembre de 1892, este llamado dice así:

Tenemos hoy un ejército de jóvenes que puede hacer mucho si es debidamente dirigido y animado. Queremos que nuestros hijos crean la verdad. Queremos que sean bendecidos por Dios. Queremos que participen en planes bien organizados para ayudar a otros jóvenes.
Prepárense todos de tal manera que puedan representar debidamente. $^{1}$

Dios levantó este ministerio en su Iglesia para que a través del dinamismo, la fortaleza y el entusiasmo se pueda culminar con la predicación del evangelio.

\section{Fechas importante en la organización del Ministe- rio Joven Adventista (J.A.)}

» 19 de diciembre de 1892:

El primer mensaje de Elena G. de White acerca del trabajo de los jóvenes.

» 1879 a 1901: Organización de varias sociedades JA en diversas iglesias.

» 1893: Se organiza en Lincoln Nebraska, la Sociedad de Jóvenes de Servicio Cristiano.

„1894: Luter Warren organiza Banda Rayos de Sol.

» 1901: La conferencia General encarga al departamento de Escuela Sabática la dirección de los Jóvenes.

»1907: En suiza, se organiza el

1 Boletin de la Asociación General, tomo 5, N. ${ }^{\circ}$ 2, 29, 30; 24 de enero de 1893. 
Departamento de Jóvenes.

»1907: En Ohio, doscientos delegados buscan el nombre oficial: Departamento de Jóvenes MisionerosVoluntarios

\section{Ideales de los J.A.}

\section{Bandera}

\section{Blanco - Pureza \\ Rojo - Redención \\ Amarillo - Excelencia \\ Azul - Lealtad}

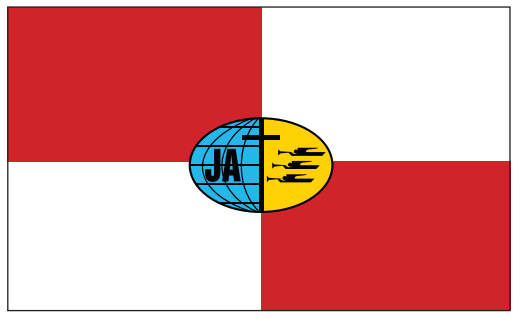

\section{Símbolo J.A.}

Mundo - Nuestra misión

Tres ángeles - Triple mensaje angélico (Apocalipsis 14)

Cruz - Centro del mensaje de la Iglesia adventista. Además se adopta el plan de la devoción matutina y el curso de lectura MV.

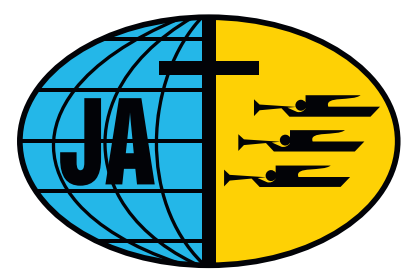

\section{El blanco J.A.}

"El mensaje del advenimiento a todo el mundo en esta generación”. Basado en Mateo 28:18-20

\section{El lema J.A.}

"El amor de Cristo me motiva". Basado en 2 Corintios 5:14.

\section{El voto J.A.}

"Por amor al Señor Jesús, prometo tomar parte activa en los deberes de la Sociedad de Jóvenes, haciendo todo lo que pueda para ayudar a otros y para terminar la obra del evangelio en todo el mundo". 


\section{El propósito J.A.}

"Los jóvenes por los jóvenes, los jóvenes por la Iglesia, los jóvenes por sus semejantes". Inspirado en el eslogan "Comparte Tu Fe", que en 1974 motivó la conquista de jóvenes en todo el mundo.

La declaración de misión de los J.A. (versión resumida)

"Trabajar en favor de los jóvenes, promoviendo el compañerismo y el fortalecimiento espiritual, capacitándolos para el servicio de la Iglesia y la comunidad".

\section{Liderazgo (módulo II)}

El Ministerio Joven desarrolla cursos en Liderazgo JA, Conquistadores y Aventureros que sirven como base para el liderazgo de la iglesia local. En los ideales del Ministerio Joven encontramos el objetivo más importante: "Salvar del pecado y guiar en el servicio". Elena G. de White da algunos consejos a los jóvenes y a los que trabajan con ellos. "Vi que muchas per- sonas se salvarían, si los jóvenes estarían en el lugar que deberían estar, consagrados a Dios y en la verdad..." 2

A medida que el tiempo pasa, vemos cómo los principios y los valores parecen desmoronarse con increíble velocidad. Una edición especial de Veja Jóvenes, en junio del 2004, decía, "Tenemos una generación soñadora pero también realista...su mayor miedo es la violencia, y el 99\% cree en Dios, están preocupados en aquellas cosas que puedan afectar su felicidad".

\section{Desafío}

Pero ¿cómo involucrar a los jóvenes en el evangelismo?, es necesario que se involucre a los jóvenes en el cumplimiento de la Misión. Aunque la investigación muestra que el 99\% cree en Dios, esto no es suficiente para conducirlos al cielo; nuestro desafío como líderes de jóvenes es llevarlos a la

2 Elena G. de White, Mensajes para los Jóvenes (Buenos Aires: ACES, 1990), 206. 
Cruz de Cristo, prepararlos y guiarlos en el cumplimiento de la Misión, incentivarlos para el evangelismo. Nuestro mayor desafío es mostrar al mundo lo que significa ser un joven cristiano, eso implica predicar con alegría el pronto regreso de Jesús. Al hacerlo, es importante observar y aplicar el método de Cristo.

Jesús buscaba a Dios en oración. Lucas 6:12 dice que Jesús subió al monte para orar y allí pasó la noche, orando. En el pasado, los grandes líderes dedicaron horas buscando la aprobación de Dios a través de la oración. En el liderazgo de hoy, la oración es tan importante como en el pasado.

Jesús evangelizaba primero a los de casa. La mayor preocupación de Jesús fue la evangelización de sus discípulos (Mc 3:14). Nuestra prioridad debe ser nuestros propios jóvenes, muchos de ellos andan desorientados, van para la Iglesia, pero no están comprometidos con los principios.
Jesús iba donde estaban las personas. Jesús iba a buscar a las personas donde las podía encontrar (Mc 2:1; 3:1,20). Antes de presentarles los proyectos a los jóvenes, necesitamos pasar tiempo con ellos, ayudándoles en sus necesidades; ellos quieren ser amados, apreciados y valorados.

Jesús descubría las necesidades de las personas. Jesús suplía las necesidades de las personas; el líder debe descubrir cuáles son las necesidades de sus liderados, atendiendo las necesidades de las personas tendrá éxito en sus proyectos.

Jesús ofrecía soluciones. El líder debe estar siempre en el momento preciso para atender las necesidades de sus liderados, llegar días después ya no ayuda, no se puede resolver nada; ofrezca la solución en el momento preciso. Organice a los jóvenes de la Iglesia y trabaje los proyectos evangelísticos y comunitarios, estos tendrán mayor efecto si el grupo está comprometido. 
Estrategias para involucrar a los jóvenes en el cumplimiento de la misión

Todo líder de jóvenes se pregunta: ¿Cómo puedo involucrar a los jóvenes en la Misión? Aquí, algunas sugerencias:

1. Céntrese en la Misión y no en los problemas. La mayor alegría será que un joven conduzca a una persona a los pies de Cristo, cumpliendo la Misión muchos de sus problemas habrán encontrado solución.

2. Escoja un proyecto. Desarrolle un proyecto que armonice con el estilo de vida de sus jóvenes y las necesidades de la comunidad.

3. Estimule los métodos conocidos y aproveche las nuevas ideas. Los jóvenes se involucran con aquello que funciona, motívelos para que piensen en ideas innovadoras.

4. Planifique y organice un proyecto. Debe conocerse el rumbo del proyecto, la ruta debe estar bien trazada con los puntos claros.

5. Prepare una investidura en Evangelismo Joven.

6. Desafíe a los jóvenes a lograr grandes cosas. Permita que utilicen sus talentos y, con la ayuda del Espíritu Santo, lograrán mayores resultados.

7. Ayúdelos con entrenamiento y materiales. Un ejército bien entrenado y con los materiales adecuados, obtendrá resultados exitosos.

8. Muéstreles confianza y apoyo. Los jóvenes hacen mejor el trabajo si saben que su iglesia y sus líderes los apoyan.

9. Ore con los jóvenes y por ellos. El evangelismo es una obra espiritual.

Necesitamos involucrar más a nuestros jóvenes en el cumplimiento de la Misión, nuestro desafío es entrenarlos e involucrarlos para que hagan la obra con alegría y entusiasmo, hablar todos el mismo lenguaje, mirar en la misma dirección; jóvenes comprometidos, capaces de dar 
todo por Jesús, así como en el pasado los líderes dieron su vida por el evangelio.

\section{Siete cualidades de un líder de jóvenes}

El mundo actualmente está enfrentando cada vez más problemas, nunca antes la palabra "crisis" ha tenido tanto significado como ahora. La Iglesia no es ajena a esta necesidad. "La mayor necesidad del mundo es de hombres que no se compren ni se vendan; hombres que en lo más íntimo de su alma sean verdaderos y honestos; hombres que no teman llamar al pecado por su nombre; hombres cuya conciencia sea tan fiel al deber como la brújula al polo; hombres que permanezcan firmes aunque se desplomen los cielos"3. Es por ello que un líder cristiano debe hacer un análisis de su carácter y sus cualidades, y dejar que el Espíritu Santo haga su trabajo.

Un líder debe tener las siguientes cualidades:

3 Elena G. de White, La educación (Buenos Aires: ACES, 1990), 55.
Humildad. Debe reconocer sus limitaciones tal como Moisés lo hizo (Ex 4:10), no debe ser autosuficiente, debe cuidar de mostrar una falsa humildad pues esto puede arruinar su liderazgo. Hacer la voluntad de Dios. Un líder debe seguir la voluntad de Dios. El verdadero éxito para un líder cristiano radica en seguir la voluntad de Dios.

Tener metas claras. El fundamento de todo liderazgo consiste en tener la visión clara, sin embargo, el mayor problema que enfrenta un líder no es la falta de visión, sino la falta de metas que lo conduzcan por el verdadero camino de un liderazgo eficiente.

Ser perseverante y valiente. Una de las grandes necesidades del mundo y de la Iglesia es la de líderes que lleguen a donde van. Ejemplo de ello son: Guillermo Miller, Jaime White, Elena Harmon, Urias Smith, entre otros. Saber superar adversidades. Es indispensable reconocer que, a partir de una frustración o crisis, puede surgir una gran oportunidad para el éxito. Un líder tiene que estar dispuesto a superar las adversidades que se presentan 
en el desarrollo de sus proyectos, hacer los cambios necesarios en su proyecto e involucrar a su grupo y avanzar.

Trabajar en equipo. Un líder de jóvenes tiene que involucrar, en su directiva, al grupo con el que trabaja, darle a cada uno de sus integrantes una responsabilidad para cumplir. Si usted involucra a su equipo, tendrá el éxito asegurado, el ejemplo de Moisés es digno de imitarlo (Ex 18:1-27).

Tener dominio propio. Debemos permitir que Dios modele nuestra vida y controle todo nuestro ser, nuestro liderazgo debe ser inspirador, manteniendo siempre la cordura y el buen humor frente a las circunstancias adversas.

\section{Estilos de liderazgo}

En la actualidad, hablar de liderazgo es crucial, todo el movimiento de la interacción global requiere de grupos y organizaciones para llevar adelante sus objetivos, pero estos a su vez necesitan de líderes, y el éxito del líder depende de orientar de manera correcta a sus liderados.
Existen varios conceptos de liderazgo, todos apuntan al cumplimiento de responsabilidades, metas y al trabajo en grupo, cuando el líder asume la responsabilidad, tiene varias formas para cumplir sus metas, él elige qué tipo de liderazgo utilizará para el trabajo grupal:

\section{Líder autócrata y autoritario.} Toda la responsabilidad se centra en el líder, él motiva, decide y controla a sus liderados, asume que solo él es capaz de tomar decisiones importantes.

Líder participativo. Usa las consultas en la práctica del liderazgo, no delega su derecho a tomar decisiones finales, pero da directrices específicas a sus liderados, escucha a sus liderados, valora sus ideas y acepta sugerencias positivas y prácticas.

Líder permisivo. En este estilo el líder delega a sus liderados la autoridad para tomar decisiones, espera que sus liderados asuman responsabilidades por su propia motivación, dirige y controla respetando un mínimo de reglas.

Existen varios estilos de liderazgo, cada uno con sus carac- 
terísticas, aciertos y desaciertos. Mientras Jesús estuvo en esta tierra nos mostró una manera de liderar, Él condujo a su grupo y logró los objetivos, a través de su liderazgo nos enseñó aspectos importantes que deben ser tomados en cuenta.

\section{Los 10 mandamientos del liderazgo exitoso}

Primero: Entrega. Abnegación para darle prioridad a los intereses del liderazgo por encima de sus propios intereses.

Segundo: Valor. Capacidad para enfrentar las situaciones de peligro y desánimo, para enfrentar momentos difíciles y correr riesgos sin temores.

Tercero: Toma de decisiones. Tomar decisiones firmes y con rapidez. Cuando otras personas vacilan, él tiene que comprometerse, especialmente en situaciones difíciles.

Cuarto: Persuasión. Carisma y habilidad para convencer y ganar la voluntad de los demás en favor de las metas y aspiraciones propuestas.

Quinto: Humildad. Esta virtud modera cualquier autoestima elevada o exaltación propia.

Sexto: Responsabilidad. Madurez para reaccionar tanto en el fracaso como en el éxito.

Séptimo: Aptitud. Disposición para hacer las cosas bien, conjunto de habilidades y destrezas en un área específica de su trabajo.

Octavo: Entusiasmo. Cualidad contagiante y que se puede involucrar como un estilo de vida.

Noveno: Integridad. Ser un modelo de identificación a través de una conducta coherente con sus ideas.

Décimo: Generosidad. Actitud indispensable en la vida de un líder, debe compartir el éxito con los demás para que lo alcanzado sea reconocido.

\section{Consagración (módulo III)}

Nunca ha sido más importante la formación de nuevos líderes, para satisfacer las múltiples necesidades de un mundo que cambia rápidamente. La esencia del liderazgo radica en la preparación, la integridad y el ejemplo personal y sus acciones están relacionadas con la solidaridad, el afecto, la confianza, la fuerza y la imaginación. 


\section{La importancia del estu- dio de la Biblia}

Considero, queridos líderes, que es indispensable para el líder moderno el conocimiento de la Biblia, de su historia y la evolución de la sociedad a la que pertenece. Recomiendo encarecidamente la lectura de las biografías de los grandes personajes bíblicos como sus consejos y enseñanzas. La Biblia es la mayor obra de fe. ¡El mayor compendio de la Verdad! y la Piedra Angular de la familia. El libro que más vidas ha transformado y sigue transformando.

Las vidas de los grandes patriarcas del Antiguo Testamento es un compendio de liderazgo muy actual. Da paciencia en las pruebas, la confianza en la dirección de Dios, asegura de que el trabajo es de Él, por eso las decisiones y soluciones de los problemas provienen de Él. Incluso hoy en día estos ejemplos de paciencia, organización, tolerancia, firmeza e integridad trazan un camino seguro en el liderazgo joven.
El profeta Isaías dice: "No temas, porque yo estoy contigo; no desmayes, porque yo soy tu Dios que te esfuerzo; siempre te ayudaré, siempre te sustentaré con la diestra de mi justicia" (Isa 41:10) David, dice: "Te instruiré y te enseñaré el camino en que debes andar, te aconsejaré con mis ojos puestos en ti". (Sal 32:8) ¿Cuánto necesitamos de la Biblia? Jesús dijo con autoridad:

"No solo de pan vivirá el hombre, sino de toda palabra que sale de la boca de Dios" (Mt 4:4).

Hay en la Biblia 31.173 versículos, 1.189 capítulos y 66 libros; Dios puso vida en cada palabra. Nuestra alimentación física consiste en cereales, verduras, frutas y otros que preparan para nuestro bienestar físico. Del mismo modo, la Biblia contiene promesas, instrucciones, poesías, himnos, historias, exhortaciones, cronologías y otros tipos de texto. Recordemos siempre que hay vida en cada palabra, para recibir alimento espiritual, la fuerza y la salud mediante la lectura de 
toda la porción que leemos todos los días.

Lea siempre la Biblia, ¿Has llegado a la mitad? Termine la lectura hasta fin de año. ¿Ha terminado de leer? Empieza a leer de nuevo. ¿Nunca lograste comenzar a leer la Biblia? Comienza hoy, únete al plan: Reavivados por su Palabra, lee un capítulo por día. Un encuentro con la Biblia significa apartarse del mal y tener un corazón alegre.

\section{Espiritualidad del líder}

Si su pregunta es cómo ser un líder espiritual, mi pregunta es: ¿Para qué? ¿Cuál es su motivación? La respuesta va a determinar el curso de su espiritualidad y de su vida. Si desea ser espiritual solo para obtener respeto e influencia, solo está pensando en su responsabilidad como líder, ipero la vida eterna puede estar en juego!

Si su deseo es ser un líder espiritual para alcanzar el favor de Dios y la vida eterna, está en el camino correcto. "Ser líder" es algo temporal, el deseo de ser espiritual debe estar completamente desconectado del papel que usted desempeña. Lo que está en juego no es su función (eso es pasajero), es la vida eterna.

David fue una persona que nunca se dejó engañar por la posición, era muy consciente de que cada dirección espiritual representa un alto riesgo de destrucción, si se da lugar a la arrogancia o a la hipocresía. Tal vez por eso gritó: "Crea en mí, oh Dios, un corazón limpio..." (Sal 51:10). Su preocupación no era la apariencia, sino lo íntimo de su corazón. Entre sus mayores virtudes estaba la honestidad, al igual que usted y yo, él sabía que su corazón no era puro por naturaleza. Así que, si este es nuestro caso, ¿cómo lograr la rectitud de corazón para ser un líder verdaderamente espiritual, que agrade a Dios?

\section{Cómo ser un líder espiritual}

La gran mayoría de los cristianos saben qué hacer, pero ig- 
noran el cómo. En 2 Corintios 3:18 Pablo indica lo que se debe hacer: "Por tanto, nosotros todos, mirando con el rostro descubierto, contemplando como en un espejo la gloria del Señor, somos transformados de gloria en gloria en la misma imagen, como por el Espíritu del Señor”. ¡ Esta es una ley que rige la mente humana que por la contemplación somos trasformados! Hasta el enemigo de Dios sabe que todo aquello que se pone en contacto con nosotros, puede transformarnos y él se aprovecha de este hecho muy bien. El lado positivo es que cuanto más tiempo pases con Cristo, serás más semejante a Él.

Pero todo el mundo sabe que usted debe tomar tiempo cada día para orar, meditar en Jesús, leer la Biblia, estudiar la lección, leer con regularidad los libros de Elena G. de White, hacer el culto familiar, el trabajo misionero, asistir a la iglesia y caminar con el Señor el resto del día. Pero quizás una de las razones para el fracaso es la falta de conocimiento de cómo hacer esto, y cómo esto tiene que ver con sus hábitos.
Dios nos dice, a través de los escritos de Elena G. de White, que lo único que llevamos al cielo es el carácter, que a su vez está formado por todos los hábitos que desarrollamos en esta vida. ¡Los hábitos tienen una enorme importancia para la salvación! Pero, ¿qué es un hábito? Es una acción o actitud que, de tanto ser repetida de la misma manera, se convierte en algo natural y casi automático. Pero ¿qué tiene que ver los hábitos con la comunión con Dios? La verdad es que mientras alguien no forma el hábito de mantener la comunión regular y diaria con Dios, tendrá una vida espiritual fracasada. ¿Y cuál es el secreto para formar un hábito? Está en la repetición de los hechos que, por cierto, algunas personas detestan.

La causa del fracaso espiritual de muchos miembros de la Iglesia es creer que se puede desarrollar la comunión con Dios, sin la necesidad de formar el hábito. La comunión no debe depender de nuestros impulsos, pero sí es una decisión soberana de la voluntad. A medida que nuestros impulsos son volubles, pronto 
descubriremos que no podemos tener comunión con Dios sin desarrollar el hábito, y esto no se hace realidad sin sacrificio y negación del yo. De hecho, solo tendrán disposición para hacer este sacrificio, si usted tiene el fruto del Espíritu: el dominio propio o templanza. Esta virtud nos lleva a determinar cuándo es necesario decir "no" a sí mismo, e ir en contra de su propia voluntad.

Es el dominio propio que nos lleva a ver el "yo" tan perezoso y pecador, que no quiere despertar o levantarse temprano, como

un enemigo a ser derrotado, esa es la lucha diaria de vida o muerte. Por eso Jesús dijo: "Si alguno quiere venir en pos de mí, niéguese a sí mismo, tome su cruz cada día, y sígame" (Lc 9:23). Jesús dejó muy claro que "sin mí nada podéis hacer", incluso no podemos tener comunión con Él (Jn 15:5). El apóstol Pablo, nos hace entender que es Dios "quien obra en vosotros tanto el querer como el hacer, por su buena voluntad", lo que significa que tanto, querer como hacer (tener) la comunión con Dios, es parte de un milagro.
Pero usted puede facilitar el proceso comiendo temprano, $\mathrm{y}$ yendo a la cama más temprano. Creo que una de las principales trampas que Satanás tiene para nosotros, los creyentes de los últimos días, es tratar de mantenernos fuera de la cama por la noche. Él sabe que si me acuesto tarde, será difícil mantener el hábito de comunión con Dios en las primeras horas del día siguiente.

Recuerde que un buen hábito se adquiere con mucho sacrificio (y es siempre un sacrificio), pero se puede perder muy rápidamente. Es por eso si hoy leo la Biblia será mucho más fácil leerla mañana, pero si no la leo hoy, será más difícil leerla mañana.

¿Qué estás esperando? Uno de las mejores herramientas para empezar es la jornada espiritual de las 40 madrugadas con Dios. Sin embargo, usted puede comenzar a desarrollar el hábito ahora mismo. En oración, escoja una hora (tan pronto como usted se despierta), un lugar sin bulla y tranquilo para su comunión permanente (oración, 
la lectura de la Biblia, el estudio la lección y del Espíritu de Profecía). Programe la alarma en su celular para hacerle recordar el compromiso más importante del universo: el contacto con su Creador, con cita previa. Esto es lo que Jesús prometió para usted: "Al vencedor le daré que se siente conmigo en mi trono, así como yo he vencido y me senté con mi Padre en su trono" (Ap 3:21).

\section{Discipulado (módulo IV)}

\section{Introducción}

Cada año, cerca del 50\% de las personas que entrega su vida a Cristo por medio del bautismo, son jóvenes. Pero, con tristeza se ve a otros abandonar la fe, debido a la falta de atención e involucramiento en las actividades de la Iglesia. Otro número de jóvenes se encuentra en la Iglesia, pero no participa de sus actividades, y es un pequeño grupo de jóvenes el que está involucrado en el liderazgo de la Iglesia. ¿El Ministerio Joven tiene algo que hacer al respecto?.

El líder del Ministerio Joven debe saber que llevar almas a los pies de Jesús, no es todo, pues el sueño de Dios es que el joven se integre y participe en las actividades misioneras de la Iglesia. Antes que Jesús fuera al cielo, Él entregó a sus discípulos una grande comisión, que dice:

"Por tanto, id, y haced discipulos a todas las naciones, bautizándolos en el nombre del Padre, y del Hijo, y del Espíritu Santo; enseñándoles que guarden todas las cosas que os he mandado; y he aqui yo estoy con vosotros todos los dias, hasta el fin del mundo. Amén" (Mt 28:19,20).

\section{La gran comisión es hacer discípulos}

¿Qué es hacer discípulos? Es un proceso continuo por el cual la persona que es atraída a Jesús, es desarrollada y convertida en un creyente maduro que reproduce su experiencia en otros. Cuando el Ministerio Joven involucra activamente a sus miembros en el ciclo del discipulado, ocurre que:

»Comprenden la orden de Jesús. 
» Facilitan el desarrollo espiritual de los jóvenes.

»Aumentan el número de los misioneros voluntarios.

»Se disminuye la apostasía.

¿Cómo podemos hacer para que un joven sea un discípulo y que a su vez pueda discipular a otros? Para lograr este objetivo, en primer lugar, el Ministerio Joven de la Iglesia, debe tomar la decisión de comenzar y continuar este proceso, hasta lograr el objetivo. Una vez decidido, se debe pasar por tres fases:

\section{Primera Fase: La}

Conversión

El objetivo de esta fase es tener el mayor número de jóvenes no adventistas estudiando la Biblia, es decir, se debe preparar bien a los candidatos al bautismo, mediante el estudio de una serie completa de estudios bíblicos, algunos métodos para conseguirlo son:

»El ministerio del servicio. Es un método que atrae a personas por medio de la simpatía, soluciona las necesidades y termina con el "sígueme", tal como lo hacía el Señor Jesús. En nuestros días, el Ministerio Joven de la Iglesia puede realizar actividades como: la oración intercesora, parejas de oración, proyecto vida por vidas, encuentro de casados, ADRA, escuela para padres, cursos de salud, compartir el pan, etc.

» Actividades de proclamación. Los estudios bíblicos en hogares, las clases bíblicas, los grupos pequeños y el evangelismo público.

»Actividades de persuasión. Las semanas de cosecha, semanas de oración, la voz de la juventud, las caravanas de la esperanza, etc.

\section{Segunda Fase:}

\section{La Confirmación}

Cuando un joven se bautiza, está apenas comenzando, será necesario consolidar todo lo que fue aprendido y reafirmar sus decisiones. Es necesario que lleven un estudio avanzado como una lección de Escuela Sabática, donde puedan conocer acerca de los tres aspectos: la comunión, las doctrinas, la vida 
cristiana, y la Misión. Además el joven bautizado debe ser involucrado inmediatamente en un Grupo Pequeño, para dar continuidad al ciclo del discipulado.

\section{Tercera Fase: \\ Capacitación Misionera}

En esta fase se tiene por objetivo entrenar y equipar al recién bautizado para desarrollar la misión. Para lograr esta fase, la Iglesia debe tener organizada la "Escuela Misionera". En ella se deben dictar las materias básicas que prepararán, al recién bautizado, en su quehacer misionero por Cristo. La dosificación de materias podría ser la siguiente:

\section{» Descubriendo los dones es-} pirituales: dos horas de clase.

"Actividades del ministerio del servicio: con una hora de clase, cuyo contenido a desarrollar son: las parejas de oración, proyecto vida por vidas, encuentro de esposos, ADRA, escuela para padres, cursos de salud, etc.

» Entrenamiento para actividades externas: con seis horas de clase, cuyo contenido son: el testimonio personal, la visitación, el estudio bíblico, cómo puedo llevar a personas a decidir por Cristo, cómo dirigir una clase bíblica, cómo liderar un grupo pequeño.

\section{La atención a las mentes seculares}

Para poder evangelizar a los jóvenes en nuestros días, en primer lugar, debemos comprender el mundo en el cual ellos viven: el posmodernismo. También debemos preparamos para enfrentar los desafíos que eso representa pues, de lo contrario, podríamos

» Ser devorados por esa forma de vida y pensamiento.

» Nosotros debemos esforzarnos para predicar del evangelio, de lo contrario sería ineficaz el evangelio en nuestros días.

Cabe destacar que el posmodernismo es una forma de entender la vida, la moralidad y la espiritualidad y, además, una cosmovisión radicalmente distinta de la cosmovisión cristia- 
na. El mundo posmoderno está inmerso en filosofías como el hedonismo, el individualismo, el utilitarismo y el pragmatismo.

1. El individualismo y el hedonismo. Se centra en el desarrollo personal, una facilidad propia, un trabajo adecuado, etc.

2. El pluralismo. Le gusta de pensamientos radicales y vive en armonía con todas las culturas, por eso deja de buscar la verdad absoluta, no cree en ella, pues cree que todo es relativo.

3. Siento luego existo. El joven valoriza el sentimiento, las emociones por encima de la razón, por eso, primero experimenta y luego piensa.

\section{La adoración (módulo V)}

Los jóvenes han sido llamados para ser líderes y para adorar a Dios, no se puede decir que es cristiano mientras que no adora a su Creador. Es por ello que la adoración cumple una función primordial dentro del crecimiento del joven adventista.
Sus gustos, sus acciones, sus pensamientos deben ser purificados para un mejor desenvolvimiento dentro del cuerpo de Cristo. Esto se verá reflejado en sus relaciones dentro de la Iglesia y fuera de ella, así como también en su forma de notar la presencia de Dios en cada acto de su vida; pero todo esto va a ser el producto de la relación con su Creador.

El papel que debe cumplir la Iglesia, en relación a sus jóvenes, es el de crear un ambiente propicio para el desarrollo de sus cualidades y dones. Dicho ambiente debe estar nutrido de tal manera, que puedan cumplir con la misión de la Iglesia: Proclamar el mensaje de salvación a sus semejantes. Nada de lo que se haga, dentro de la programación de la Iglesia, debe desvirtuar ese objetivo. Estaremos adorando a Dios al predicar el evangelio eterno, tanto en forma verbal, como también a través del estilo de vida.

Dentro de la forma de adorar a Dios también está la comprensión que se tenga de Él. De acuerdo cómo se lo considere, se lo adorará. Es por ello que la 
Iglesia, su estructura y sus actividades, deben propiciar la conciencia de la presencia de Dios en la vida del joven. Tanto dentro de los ambientes de la iglesia, hasta donde se desenvuelve fuera de ella, el joven debe considerar que a su lado está Alguien que lo ama. Ello se verá reflejado en la forma en que presta reverencia en la iglesia, cuando trabaja, cuando estudia e incluso cuando enamora. La respuesta del joven adorador corresponderá al de un Dios amoroso. Su presencia en la Iglesia, sus reglas y requerimientos, será placentera y lo conducirá a influenciar en los demás.

Durante mucho tiempo se ha gastado tinta y papel en disertaciones acerca de qué música debe escuchar el joven adventista. Prolíficos defensores de la verdad han amontonado motivos y argumentos para "controlar" o "liberar" al joven de la influencia de la música perjudicial. Y, aunque no todo está dicho, al menos debería considerarse algunos principios que guíen dicha elección.

La música que se escucha de- bería edificar al oyente. Debe hacerlo sentir en la presencia de Dios. Algún valor moral o principio que ayude al crecimiento espiritual, debe extraerse de ella. No debe mezclarse lo santo con lo secular, con el fin de hacerla más atrayente. Dios no usa instrumentos del diablo para salvar a los creyentes. La música debería ser adecuada para el momento y la ocasión. Debe promover el respeto y la reverencia a Dios. No debe promover la sensualidad, ni tampoco la satisfacción de los sentidos. Debe glorificar a Dios.

Además de los estilos musicales, se debe considerar quién es el que interpreta la música.

El músico debe ser una persona consagrada a Dios. No debe ser una persona competitiva, ni imitar estilos de otros, pues no sería natural, sino fingido. El hecho de sentir la presencia de Dios, en cada momento de mi vida, hará que pueda elegir la música que a Dios le agrada, y adorarle como Él se merece.

En estos tiempos finales, la adoración y la obediencia, son 
los puntos por los cuales nos haremos siervos de Dios o siervos del maligno. De la elección que hagamos dependerá nuestra vida eterna.

\section{Compañerismo (módulo VI)}

¿Cómo aconsejar a los jóvenes?

Para aconsejar a los jóvenes, de hoy en día, es necesario comprender las cosas que ellos consideran más importantes, estas son:

\section{Apariencia física}

La moda, a través del tiempo, se ha convertido en la tendencia que retiene la atracción de muchos y en especial de los jóvenes.

El consejo moderado, para estos, debería ser buscar el equilibrio entre lo ostentoso y lo conservador, evitar los extremos. Otro aspecto es el cuidado excesivo de la apariencia física, hay quienes no están felices con su apariencia, buscan cambiar su figura, sometiéndose a cirugías estéticas y operaciones complejas; porque no se sien- ten amados/as y valorados/as. Debemos aceptarnos como somos, la Biblia aconseja

"Que la belleza de ustedes no sea la externa, que consiste en adornos tales como peinados ostentosos, joyas de oro y vestidos lujosos. Que su belleza sea más bien la incorruptible, la que procede de lo intimo del corazón y consiste en un espiritu suave y apacible. Esta si que tiene mucho valor delante de Dios". (1 Pe 3:3,4).

\section{Reuniones sociales}

"Porque todos vosotros sois hijos de luz e hijos del dia; no somos de la noche ni de las tinieblas". (1Ts 5:5)

La Iglesia debe tener sólidos programas diurnos, que integren y mantengan ocupados y activos a los jóvenes, para que sean conducidos por el buen camino participando de deporte, música, culto joven, celebración de cumpleaños y programas culturales. Un joven bien atendido socialmente dentro de la Iglesia estará fuera del alcance de la ten- 
tación de la noche.

\section{Amistades}

Los jóvenes suelen reemplazar a los hermanos y padres por los amigos, quienes se convierten en sus principales consejeros; nosotros no podemos impedirlo pero sí enseñarles a buscar buenos amigos, una amistad puede ser una bendición o una maldición.

Enséñeles a tener cuidado de los amigos de lenguaje vulgar, que menosprecien las cosas espirituales, que tienen vicios, costumbres prohibidas, liberales y que no tienen metas en la vida.

\section{Enamoramientos}

Los jóvenes no tienen la culpa de la sociedad ni de la época en la que nacieron, la degradación moral cada vez es más fuerte y en la sociedad requiere que "debemos establecer reglas y recursos que los protejan de muchos daños, dejando de esta manera abierta las puertas de la fornicación”. Sin embargo, la Biblia establece que es pecaminoso y perjudicial tener relaciones sexuales antes del matrimonio, al igual que en los tiempos de José y Pablo.

Debemos evitar jugar con los sentimientos de las personas y dedicarnos a una o uno en especial, pidiendo a Dios nos mantenga castos y vírgenes hasta el día del matrimonio. "El amor es una planta de crecimiento celestial y debe ser nutrida y alimentada. Los corazones afectuosos, las palabras veraces y llenas de amor producirán familias felices y originarán una influencia elevadora sobre todos los que entren en contacto con la esfera de su influencia”. ${ }^{4}$

\section{Principios de recreación saludable}

Es importante diferenciar recreación de diversión, la palabra recreación proviene de "recreación" que tiende a fortalecer y construir. "Apartándonos de nuestros cuidados y ocupaciones comunes, provee descan-

4 Elena G. de White, Cartas para los jóvenes enamorados (Buenos Aires: ACES, 1990), 30,31. 
so para la mente y el cuerpo" 5 . Y la "diversión” tiene objetivos menos nobles: "buscado con el fin de proporcionar placer, es muchas veces llevado a un exceso, que absorbe las energías necesarias para el trabajo útil y, de esta manera, resulta un estorbo al verdadero éxito en la vida" 6 .

La recreación es una necesidad para todo ser humano, por eso el enemigo ofrece muchas opciones que pueden ser destructivas para nuestros jóvenes como los juegos de dinero, cartas, de azar, teatro, ópera, danza, etc.

Debemos convencernos, que atender a los jóvenes en la Iglesia no solo se trata de programas, retiros e inspiradores cultos, santa cenas, vigilias o conjuntos musicales. Tengamos en mente el concepto de E.G. White "crecimiento armónico que incluye una vida física, mental y espiritual".

Debemos llenar de actividades los sábados de noche con reuniones sociales como cenas, deportes, serenatas, juegos de salón,

5 White, La educación, 207.

6 Ibid. películas, caminatas, programas temáticos, etc., que fortalezcan la unidad entre los jóvenes, cuidándose de la competitividad egoísta.

Estas deben ser prácticas apropiadas y definidas, que reflejen el estilo de vida adoptado por los adventistas del séptimo día. Y "El anhelo continuo de recreación agradable no incentivará los profundos deseos de nadie. Pero los que beben de esta fuente de placer mundano, se dan cuenta que sigue insatisfecha la sed de su alma. Están engañados; confunden la alegría con la felicidad y, cuando cesa la agitación, muchos caen en las profundidades de la desesperación y desánimo"?

El líder analice lo siguiente, antes de organizar un programa:

» ¿La actividad le acerca a Dios o quita el deseo de orar?

¿ ¿Promueve integridad y autocontrol?

» ¿Fortalece la resistencia a la tentación?

7 Ellen G. White, Fundamentos de la Educación Cristiana, (Buenos Aires: ACES, 1990), 422. 
» ¿Qué influencia tendrá la recreación sobre la salud física y mental?

¿ ¿Vale la pena gastar el tiempo y dinero que requiere?

» ¿Desenvuelve la cortesía, la generosidad y más respeto por los otros?

» ¿Estimula la bondad o conduce el uso de la fuerza y la brutalidad?

Al terminar la actividad, todos deberán sentir que son más amigos que antes, esa es nuestra responsabilidad.

\section{Planeamiento}

Así como se planean los programas de JA para todo el año, los jóvenes deben saber que, por lo menos, una vez por mes se encontrarán con sus amigos de Iglesia para confraternizar en una actividad social, el sábado de noche:

a. Tome su tiempo para las actividades sociales, las cuales podrían ser dirigidas por el director del Club de Jóvenes, Club de Conquistadores o al- guien que guste de las actividades sociales dando sugerencias para una planificación bonita.

b. No deje como último punto de agenda las actividades sociales, porque no será tratada con la atención que se merece.

c. Busque material e ideas creativas para organizar las actividades.

d. Cuide de los detalles, y lo más importante, pida a Dios su dirección en oración.

\section{Capacitación (módulo VII)}

\section{La importancia de la capa- citación}

La capacitación es uno de los módulos que ayuda a los jóvenes estar preparados para las responsabilidades de la Iglesia y ser fortalecidos en la fe por medio de las Sagradas Escrituras. La capacitación realizada por medio de las Escrituras sobre su vida espiritual y de liderazgo, ayuda a los jóvenes en la prevención de influencias conceptuales que están en contra de la completa dependencia 
del hombre a Dios y del reconocimiento de la sabiduría divina, para lograr un buen desarrollo del liderazgo que hoy el joven necesita para servir a su Iglesia.

Existen tres grupos involucrados para recibir las capacitaciones: primero, la juventud, ellos necesitan vivir una experiencia profunda y relevante con Dios. Segundo, los padres de familia, son ellos los que deben influir en sus hijos la completa dependencia en Dios y de ejercer el liderazgo para desarrollar sus capacidades para el servicio de la Iglesia. Por 156 último, está la Iglesia, la cual debe fortalecer a los jóvenes respecto al entorno para la prevención de la apostasía, brindándoles oportunidades de su liderazgo.

\section{Lecciones bíblicas sobre la importancia de la capaci- tación}

José. Fue llevado por Dios a una tierra distante que era pagana, idólatra y promiscua - Egipto. Dios llamó a un muchacho adolescente con apenas de diecisiete años de edad (Génesis 37:2). Dios normalmente no llama a los que se juzgan ser más capacitados. Dios capacita con dones especiales a aquellos a quien Él llama.

Esther, cuyo nombre significa "estrella". Una vez más el pueblo de Israel estaba cautivo en tiempos del rey Asuero, los judíos corrían el riesgo del exterminio por la crisis moral y espiritual de una nación pagana. Pero Dios, en su ilimitada providencia, tenía una estrella grande para brillar cuando parecía ser oscuro y nada promisorio. Dios capacitó a Esther para que sea un instrumento de liberación, frente a la amenaza del enemigo.

\section{Daniel, Misael, Ananías y} Azarías. Un grupo de amigos que estuvieron al servicio de Dios. Ellos fueron capacitados e instruidos en los principios de Dios desde su tierna edad, ellos no sabían el mundo que conocerían en su vida joven, la capacitación recibida en sus familias los hizo aptos para estar en el palacio del rey de Babilonia, y estuvieron dispuestos a no perder sus principios en un mundo comple- 
tamente desconocido y pagano.

Estas lecciones bíblicas resumen, primero, que Dios es un constante capacitador para fortalecer la fe de sus hijos; segundo, el hijo capacitado está listo para hacer frente a las dificultades que el mundo presenta; tercero, la práctica de las orientaciones recibidas ayudan a mantener viva la fe, y esta actúa como escudo contra la apostasía del mundo.

\section{Un llamado urgente a los jóvenes}

Dios está haciendo un llama- do a cada joven en la hora undécima. Y casi a media noche del reloj profético del cielo, Dios le está llamando para apagar las luces del presente siglo. Alístese en el poderoso ejército de Cristo porque las vacantes, para ambos sexos, son ilimitadas sobre el llamado de Dios, lea el voto de consagración en el recuadro, tome su decisión y rellénelo.

\section{Trabajando con las clases de liderazgo}

Son tres los niveles ofrecidos en el liderazgo de los jóvenes como se puede ver más adelante:

\section{Voto de consagración aceptando la respuesta al llamado de Dios}

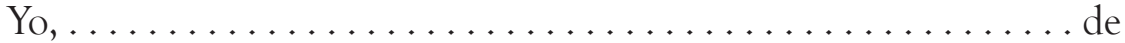

... años de edad, acepto el llamado urgente de Dios. Por la gracia de Cristo, con el poder del Espíritu Santo, acepto el desafío final de Dios, que levantar en alto la bandera ensangrentada del Príncipe Emanuel, el Salvador de la humanidad perdida. Quiero compartir, de acuerdo con los dones recibidos por Dios, el mensaje final de Cristo para mis semejantes que están perdidos en las garras del pecado, sin Jesús y sin esperanza. ¡AMÉN!

de........ . de .......... 
Primer Nivel: Líder JA, Guía Mayor de Conquistadores y Guía Mayor de Aventureros.

Segundo Nivel: Líder Máster JA, Guía Mayor Máster de Conquistadores.

Tercer Nivel: Líder Máster Avanzado JA, Guía Mayor Máster Avanzado de Conquistadores.

\section{Jóvenes Adventistas}

\section{Líder JA}

Las clases de líder Joven fueron formadas para constituir la base de los grupos de jóvenes, en estas tenemos cuatro secciones, con los pre-requisitos:

a. Crecimiento personal y espiritual.

b. Liderazgo aplicado.

c. Compromiso con la Iglesia.

d. Compromiso con el servicio.

e. Capacitación.

\section{Líder Máster JA}

a. Crecimiento personal y espiritual.

b. Liderazgo aplicado.

c. Compromiso con la Iglesia. d. Capacitación.

Líder Máster Avanzado JA

a. Crecimiento personal y espiritual.

b. Compromiso con la Iglesia.

c. Compromiso con el servicio.

d. Capacitación.

e. Liderazgo aplicado.

\section{Liderazgo de Conquistadores}

Guía Mayor

a. Crecimiento personal y espiritual.

b. Fundamento de los consejeros de los Conquistadores.

c. Servicio al club.

d. Liderazgo aplicado.

e. Capacitación.

\section{Guía Mayor Máster}

a. Crecimiento personal y espiritual.

b. Servicio al club.

c. Liderazgo aplicado.

d. Habilidades generales.

e. Orden cerrado.

f. Recreación.

g. Capacitación. 
Guía Mayor Máster Avanzado

a. Crecimiento personal y espiritual.

b. Servicio al club.

c. Liderazgo aplicado.

d. Discipulado y evangelismo.

e. Habilidad de campamento.

f. Capacitación.

g. Capacitación aplicada.

Guía Mayor de Aventureros

a. Mi Dios.

b. Mi Yo.

c. Mi familia.

d. Mi mundo.

\section{Testificación (módulo VIII)}

Los jóvenes y sus líderes deben ser estimulados, para llegar a ser un buen testimonio donde estén. Esto se logra a través de:

1. Eventos que valoricen el papel de la testificación.

2. Los programas regulares del Ministerio Joven.

3. Materiales para testificación joven.

4. Involucrar el Ministerio Joven en los proyectos misioneros de la Iglesia.

\section{Los jóvenes en la comunidad}

La visión de los jóvenes debe ser mucho más alto que solo realizar campamentos, semanas de oración, cultos jóvenes y otras actividades. La visión debe incluir programas que alcancen a toda la comunidad.

Algunos pasos para que los jóvenes impacten a su comunidad y se conviertan en agentes de esperanza:

1. Oración. Por su comunidad, con temas específi$\cos$ y de manera programada.

2. Conozca bien su entorno (comunidad).

3. Reúna diferentes voluntarios para el servicio.

4. Diseñe un plan de acción. Debe ofrecer soluciones a las necesidades y problemas del entorno.

\section{Cómo involucrar a los jóvenes en los proyectos}

Los jóvenes adventistas están dispuestos a servir, por eso es importante aprovecharlos. 
En los proyectos de jóvenes, es importante considerara lo siguiente:

1. Descubra las necesidades de su entorno.

2. Haga un estudio detallado sobre ese asunto.

3. Verifique que el proyecto no esté hecho por otros.

4. Haga algo que esté a su alcance y que sea viable.

5. Verifique que el proyecto esté de acuerdo con nuestra fe.

6. Cuente con la mayor cantidad de colaboradores posibles.

7. Haga las siguientes preguntas:

a. Qué (objetivo). Ejm. Visita a autoridades.

b. Quién (encargado). El director d Jóvenes.

c. Cuándo (fecha). Verifique la agenda de la comunidad y de la Iglesia.

d. Dónde (local). Plaza Municipal, losa deportiva, etc.

e. Por qué (motivo). Por el "Impacto Esperanza"

f. Cómo (la forma). g. Cuanto (costo)

8. Considere:

a. Consulte el programa con la Iglesia, con el pastor, con la Asociación/Misión, con el departamental de Jóvenes del campo, con la Unión, para evitar inconvenientes.

b. Presente, explique y vote el proyecto en la iglesia y la Junta Directiva de la Asociación/Misión.

c. Diseñe el proyecto con un equipo. Esté abierto a escuchar ideas.

d. Use las personas capacitadas en cada área. Use un equipo multidisciplinar y heterogéneo.

e. Realice todo con mucha oración y buscando la dirección divina.

f. Recuerde que en todo proyecto debe resaltar la Iglesia adventista y no alguna persona.

g. Una vez que esté diseñado el plan de 
acción, verifique que todo esté cumpliéndose

h. Lidere. Las personas a su alrededor son valiosas e iguales.

i. Nunca debe faltar dos palabras: ¡Muchas gracias!

j. Al presentar el proyecto en una entidad pública, llévelo por escrito. Evite jergas y también términos solamente de uso denominacional como: "Pluma inspirada".

k. Tenga presente tres cosas: Qué quiere realizar, Cuál es su público atendido y Cuál es el personal con que cuenta.

1. Si es posible, incluya a instituciones de la Iglesia como las instituciones educación y ADRA.

m. Todo proyecto debe girar en torno a dos pilares: Salvación y Servicio.

n. Puede usar para sus proyectos nombres como Asociación de Universitarios Adventistas, Sociedad de Jóvenes Adventistas.

o. No espere necesariamente agradecimientos y elogios.

\section{Misión Caleb: más que una manera de evangelizar, una manera de discipular}

En esta sección se quiere mostrar cómo Misión Caleb es un proceso de discipulado. Esto se hará analizando lo presentado por Win Arn, un experto en crecimiento de iglesias:

1. Siete amigos: Misión Caleb proporciona fuertes lazos de amistades, puesto que se trabaja en base a Equipos Caleb.

2. Identificación de dones: En Misión Caleb, el joven tiene la oportunidad de trabajar en lo que mejor sabe hacer.

3. Involucrar en las tareas de la Iglesia: Al participar en Misión Caleb, el joven 
asume responsabilidades que luego aplica en su iglesia.

4. Compromiso financiero regular: Al participar en Misión Caleb los jóvenes de vuelven más fieles, comprenden mejor sus responsabilidades financieras con la Iglesia y su misión.

5. Entender e identificar los objetivos: Cuando participan de Misión Caleb, entienden mejor la misión y los objetivos de la

6. Frecuencia en los cultos: El joven llega a ser más frecuente en asistencia a la iglesia y comprometido con las actividades de la Iglesia.

7. Identificar amigos y familiares para llevarlos a Jesús: Al volverse apasionados por la salvación de las personas, trabaja por la salvación de sus amigos y familiares.

Otras características destacables de Misión Caleb son:

1. El joven que participa de Misión Caleb se desarrolla en: salvación y servicio, comunión y misión, Biblia, oración y testimonio.

2. Como resultado de Misión Caleb, muchos jóvenes confirman su deseo de ser misioneros y pastores, de servir en diferentes áreas de la Iglesia o iniciarse en el ministerio del Colportaje.

\section{Razones por qué soy un Caleb:}

1. Porque daré parte de mi vida en favor de otros.

2. Porque me gustan las aventuras y hacer nuevos amigos.

3. Porque reconozco que Cristo cambió su corona de gloria por una corona de espinas, todo eso por amor a mí.

4. Porque quiero dejar mi huella misionera.

5. Porque quiero salvar del pecado y guiar en el servicio.

6. Porque sé que aun en me- 
dio de obstáculos, Cristo me dará la victoria.

7. Porque quiero tener una experiencia especial de intimidad con Jesús.

8. Porque quiero recibir de manos de mi Salvador la corona de justicia.
9. Por eso y mucho más, ¡Soy un Caleb!

"Salvar del pecado y guiar en el servicio" es el objetivo del Ministerio Joven. En Misión Caleb se alcanza con eficacia este objetivo. 